\title{
RECOVERY OF Cephalosporium maydis THE CAUSAL AGENT OF MAIZE LATE WILT DISEASE FROM VARIOUS PLANT PARTS WITH SYMPTOMATIC OR ASYMPTOMATIC INFECTION AND ANATOMICAL CHARACTERS OF TOLERANT AND SUSCEPTIBLE HYBRIDS.
}

El-Naggar, A. A. A.

Maize and Sugar Crops Dis. Res. Sec., Plant Pathol. Res. Inst., ARC, Giza, Egypt.

\begin{abstract}
Recovery percentage of $C$. maydis, the causal agent of maize late wilt disease, was determined under greenhouse conditions in 2010 in three plant parts; i.e. second internode of stalk above the ground level (SIS), ear shank internode (EI) and tassel internode $(\mathrm{TI})$, of ten maize hybrids with and without symptoms. The two maize hybrids, SC155 (susceptible) and SC124 (tolerant) were selected from the previous experiment to assess recovery percentage and seven anatomical parameters in 2011. These parameters were; vascular bundles number (VBN) / $0.49 \mathrm{~mm}^{2}$ of area of stalk section, metaxylum cells number (MCN), protoxylum cells number (PCN), metaxylum cells diameter (MCD), protoxylum cells diameter (PCD), maximum of scleronchyma cell layers number (MASCLN) and minimum of scleronchyma cell layers number (MISCLN). These parameters were measured at the same time in cross sections of symptomatic (SI), asymptomatic (AI) and non infected (NI) plants by the agent. Recovery percentage in plants with symptomatic infection differed among hybrids depending on the degree of tolerance. The recovery percentage ranged from 10 to $85 \%$ in SIS, from 10 to $85 \%$ in El, and from 10 to $69 \%$ in TI. In apparently healthy plants, recovery percentage ranged from 10 to $70 \%$ in SIS, from 0 to $50 \%$ in El and from 0 to $20 \%$ in TI. However, in 2011 experiment, the recovery percentage of the susceptible hybrid was significantly higher than those of the tolerant ones in all three plant parts with or without symptoms. Concerning the measurements of anatomical parameters, the susceptible maize hybrid had number of vascular bundles $/ 0.49 \mathrm{~mm}^{2}$ of section area significantly higher than those of the tolerant ones only in plant sections with symptomatic and asymptomatic infection. Also tolerant plants with $\mathrm{SI}, \mathrm{Al}$ and $\mathrm{NI}$ showed significantly higher levels in maximum number of scleronchyma cell layers than the susceptible ones indicating that disease tolerance was associated with specific structure. In summary, $C$. maydis not only had the ability to invade both the tolerant and susceptible maize plants but also moves from above ground internode to ear shank internode and tassel internode and may reach to the kernels through the cob and completing its disease cycle.
\end{abstract}

Keywords: Cephalosporium maydis, maize, Symptomatic, asymptomatic, anatomical parameters.

\section{INTRODUCTION}

Late wilt disease of maize incited by the soil-borne as well as the seedtransmitting (Michail et. al., 1999) agent Cephalosporium maydis Samra, Sabet \& Hingorani (Samra et. al., 1962 \& Samra et. al., 1963). In Egypt, The disease is a principal limiting factor in production. This disease also has been reported in India (Payak et. al., 1970) and Hungary (Pecsi and Nemeth, 1998). The agent reproduces asexually and no perfect state has been 
identified. The pathogen population, in Egypt, contains four lineages, three of which are widely distributed throughout the country (Saleh et. al., 2003).

Sabet et. al. (1970) reported that the agent grows superficially on maize roots, producing hyphae with short, brown, thick-wall, and swollen cells. It progresses inter- and intra-cellularly reaching to the root endodermis and the xylem after15 and 21days after sowing respectively. After the agent penetrates the xylem, it grows slowly at first but after 5 weeks grows faster upward (El-Fangary, 1970 \& Mansour, 1969). Previous investigators reveled that invading plants by the pathogen result in a reduction of the number (Abd El-Rahim et. al., 1998) and the size of the vascular bundles (Abd El-Ghani, 1987 ) in maize stalks, in addition to blocking in many xylem vessels (Abd ElRahim et. al., 1998 and Abd El-Ghani, 1987) and finally lack of water so wilting symptoms appear. Wilting may be appearing after teaseling stage until shortly before maturity (Samra et. al., 1963). Anatomical structure of corn roots in relation to their resistance to late wilt disease was investigated by Saeed et.al (1990). They reported that the susceptible corn inbred lines had less collenchyma cell layers in their exoderms than those of the resistant inbred lines. Also they found that the resistant lines had higher content of sclerenchyma cells in vascular bundles and higher number of xylum vessels than those of the susceptible inbred lines. El-Naggar and Sabry (2011) demonstrated that $C$. maydis invaded both the susceptible and tolerant plants and symptomless infection of maize plants by the agent was evident.

Although researchers investigated pathology and anatomy of the disease, there is no report about the recovery of the agent through up-ground plant parts of tolerant hybrids with the exception of Michail et al (1999). They attempted to isolate $C$. maydis from maize ear and seed parts obtained from infected plants or taken from lots of maize research section. Also there are more investigations about anatomical studies on plants with symptomatic infection but there are no reports on this in maize plants with asymptomatic infection by $C$. maydis.

The experiments described herein were conducted to determine, which plant parts are reached by the agent in tolerant and susceptible maize hybrids. The second objective was to determine whether infection of these hybrids (tolerant and susceptible) influences anatomical characters.

\section{MATERIALS AND METHODS}

Ten maize hybrids (Table 1) were screened for symptomatic and asymptomatic infection by $C$. maydis the causal agent of maize late wilt disease at greenhouse in 2010. At the same time the recovery percentage of the agent was assayed in three plant parts (second internode of stalk above the ground level (SIS), ear shank internode (EI) and tassel internode (TI)). In 2011 maize hybrids SC 124 (tolerant) and SC155 (highly susceptible) were chosen according their reaction in previous experiment (2010) to carry out the anatomical study. All experiments were conducted under greenhouse at Maize and Sugar Crops Disease Research Section (MSDRS), Plant Pathology Research Institute (PPRI), Agricultural Research Center (ARC) in Giza. Seed hybrids were sowed in $35 \mathrm{~cm}$-diameter clay pots infested with the agent. 
Grain sorghum colonized by C. maydis (isolate No.29, obtained from Sids Agricultural Research Station, ARC) was added to the pots (15gm/ $\mathrm{kg}$ soil). Inoculum of $C$. maydis was prepared by incubating inoculated autoclaved sorghum seed for about two weeks at $27^{\circ} \mathrm{C}$. Each hybrid was replicated in five randomized pots. Each pot was sowed by 7 seed. After 21 days the stand plants were thinned to 5/pot. Pots were approximately irrigated twice a week. Fifteen gram of P2O5 (15\%) were added before sowing meanwhile $10 \mathrm{gm}$ urea $(46.5 \%)$, as a source of nitrogen, were added twice at 15 and 30 days after planting. Disease assessment was after 105 days after sowing.

Determination of symptomatic and asymptomatic infection percentage:

For determination of symptomatic infection percentage, the number of plants showing symptoms of $C$. maydis were counted then it was converted to percentage. The incidence of asymptomatic infection percentage was based on the number of healthy appearing plants (those with no symptoms of infection) from which the agent was isolated.

Isolation of $C$. maydis from plant parts:

All symptomatic and healthy appearing plants were cut above the ground level directly and dissected into above ground internodes (first and second internode), ear shank internode and tassel internode. Plant parts were surface-sterilized by $70 \%$ ethanol and flamed. Four pieces of plant pith taken from each plant part were plated on PDA $+5 \mathrm{gm}$ yeast (Saccharomyces cerevesia) extract amended with streptomycin and incubated at $27^{\circ} \mathrm{C}$. Recovery of $C$. maydis was recorded 3-4 days after plating, and the recovery percentage in plant parts of symptomatic and asymptomatic infection was converted to a percentage.

\section{Anatomical studies:}

The experiment conducted in 2011 was to select plants with symptomatic, asymptomatic infection and non infected plants (control) of the two maize hybrids extremely differed in their reaction against $C$. maydis. The stalks, second and third internode above the ground level, of these plants were divided into two portions; the first one was used to recovery the agent as described above and the second was to the anatomical studies. Plant specimens, $3-5 \mathrm{~cm}$ long, was immediately immersed in the FAA solution (formalin, acetic acid, ethyl alcohol 70\% and water in ratio 10: 5: 50 and $35 \mathrm{ml}$ respectively) until use. The fixed specimens were dehydrated by passing through degraded series of ethyl alcohol as described by Sass (1958). Dehydration was performed in increasing concentrations of ethanol and $\mathrm{N}$ butanol series, and then embedded in a paraffin wax, $58^{\circ} \mathrm{C}$ melting point, according to Johanson (1940). Ten microns thick sections were made by a rotary microtome. Sections were mounted on cleaned slides with Haupt,s adhesive (1gm gelatin $+100 \mathrm{ml}$ water $+2 \mathrm{gm}$ phenol $+15 \mathrm{ml}$ glysrol) as mentioned by Johanson (1940). Slides were left to complete dryness for $24 \mathrm{hr}$ in dry oven at $40^{\circ} \mathrm{C}$. Sections were stained with $1 \%$ safranine and $1 \%$ light green, cleared in xylene, mounted in canda balsam and examined microscopically. Sections were photographed in OLYMPUS (BH4) microscope equipped with built in digital camera (DCM310, USB2.0) and transformed to a computer using Minise Software. Sections were tested for; fungal distribution, number of; vascular bundles / $0.49 \mathrm{~mm}^{2}$ of stalk section, 
protoxylum and metaxylum cells as well as their diameter and finally number of scleronchyma cell layer.

For measuring number of vascular bundles, ten microscopic fields with three sections (replicates) of each hybrid were used with the aid of ocular micrometer, after calibirated using $0.01 \mathrm{~mm}$ stage micrometer slide (POLAND, WARSZAW Company) at 10X. Then the values converted to the number by area $\left(0.49 \mathrm{~mm}^{2}\right)$. Concerning of the number of metaxylum and protoxylum cells as well as the number of scleronchyma cell layer, they were selected randomly using 10 vascular bundles with three replicates. Also, metaxylum and protoxylum diameters were performed with the aid of ocular micrometer after its calibration using $0.01 \mathrm{~mm}$ micrometer slide.

Statistical analysis:

All obtained data of greenhouse experiments were transformed to arcsine before carrying out analysis of variance (ANOVA) plus 0.01 to normalize and stabilize variance. Greenhouse experiments were designed as a complete randomized design in four replicates of $35 \mathrm{~cm}$-diameter clay pots in 2010 . Each hybrid was analyzed individually by ANOVA and Duncan,s multiple range test to compare means of recovery percentage among the three plant parts; first with symptomatic alone and the second with asymptomatic infection by the agent. The histograms were obtained using Excel program, Windows XP 2003. Concerning the experiment of 2011 having complete randomized design, was also performed with five replicates (pots). Analysis was performed in the two hybrids with three plant parts once in symptomatic infection and the second in asymptomatic infection. Finally, number of vascular bundles, metaxylum and protoxylum cells, diameter of protoxylum and metaxylum cells as well as number of scleronchyma cell layers were analyzed as in experiment of 2011 for the two hybrids with symptomatic, asymptomatic infection and healthy plant (non infected plant). ANOVA was performed with COSTAT version 9 software.

\section{RESULTS}

In 2010 experiment, figs 1 \& 2 , all examined hybrids showed symptoms of late wilt disease and varied in their levels of symptomatic infection percentage. The lowest degree of symptomatic infection, exhibited by SC124 and SC129, were 10 and $15 \%$ respectively. At the same time the remaining examined hybrids showed high level of symptomatic infection with the range of $50 \%$, SC122, to $85 \%$, SC123. All plant stalks with symptomatic infection were colonized by the agent where $C$. maydis was recovered. Results, figs 1 \& 2, show also that $C$. maydis reached to ear shank internode $(\mathrm{EI})$ and tassel internode $(\mathrm{TI})$ of most symptomatic plants in tolerant or susceptible hybrid with the percentage ranged from $10 \%$, SC124 to $85 \%$, SC123, and from $10 \%$, SC124, to $69 \%$, SC123, respectively. The recovery percentage of the agent obtained from tassel internode always lower than that either of ear shank internode or above-ground internode with the exception of the resistant hybrid SC124, the percentage of fungal recovery was equal in all three plant parts. 


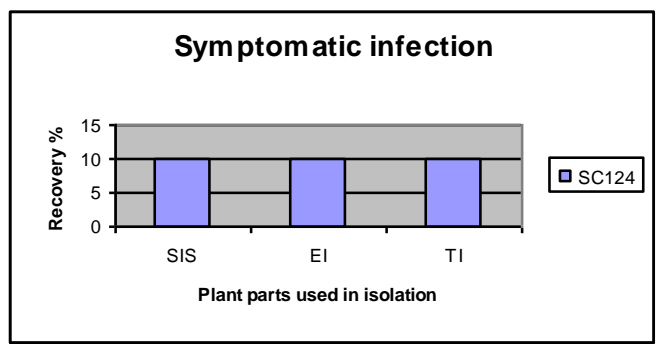

Fig.1: Recovery percentage of $C$. maydis from three plant parts of five maize hybrids with symptomatic and asymptomatic infection of plants grown in infested soil in 2010. Second internode above ground level (SIS), ear branch internode (EI) and tassel internode. $a, b, a b$ and $c$ indicates a significant differences among plant parts for recovery percentage. 
El-Naggar, A. A. A.

Fig.2:Recovery percentage of $C$. maydis from three plant parts of five maize hybrids, with symptomatic and asymptomatic infection of plants grown in infested soil in 2010. Second internode above ground level (SIS), ear branch internode (EI) and tassel internode. $a, b, a b$ and $c$ indicates a significant differences among plant parts for recovery percentage. 
Concerning healthy appearing plants, it ranged from 15 to $90 \%$. Figs 1 \& 2 show also that asymptomatic infection was in between $10 \%$, SC166-70\%, SC124. On the other hand, the agent reached also to tassel internode with recovery $20 \%$. The hybrids with the lowest degree of symptomatic infection, SC124 and SC129, exhibited the highest \% of fungal recovery in plants without symptoms (asymptomatic infection), since the recovery \% in above ground internode were 70 and $55 \%$ respectively compared with the other tested hybrids. Finally, most healthy appearing plants of the tested hybrids showed asymptomatic infection and the agent was approximately recovered from most of the three plant parts with some exception.

Concerning the experiment conducted in 2011, Table 1, show that the selected two hybrids, SC124 and SC155, varied significantly in their symptomatic infection since it was 14 and $54 \%$ respectively. Also they varied significantly in the recovery percentage from the three plant parts of plants with symptomatic infection. In contrast to results obtained in 2010, recovery \% of the second internode of the tolerant hybrid SC124 with asymptomatic infection was less than that of the susceptible ones. Results of table 1 , also revealed that there were significant differences within and between hybrids in $C$. maydis recovery percentage obtained from the three plant parts under symptomatic infection.

Table 1: Mean of infection and recovery percentage in three plant parts of two maize hybrids, SC124 tolerant and SC155 susceptible, with symptomatic and asymptomatic infection by $C$. maydis, planted in infested soil under greenhouse in 2011.

\begin{tabular}{|c|c|c|c|c|c|c|c|c|}
\hline \multirow{3}{*}{ Cultivars } & \multicolumn{4}{|c|}{ Symptomatic } & \multicolumn{4}{|c|}{ Apparently healthy plants } \\
\hline & \multirow[b]{2}{*}{$\begin{array}{c}\text { Infection } \\
\%\end{array}$} & \multicolumn{3}{|c|}{${ }^{*}$ Recovery $\%$ in } & \multirow[b]{2}{*}{$\%$} & \multicolumn{3}{|c|}{${ }^{\star \star}$ Recovery \% in } \\
\hline & & $\begin{array}{c}\text { Second } \\
\text { internode }\end{array}$ & $\begin{array}{l}\text { Ear shank } \\
\text { internode }\end{array}$ & Tassel & & $\begin{array}{c}\text { Second } \\
\text { internode }\end{array}$ & $\begin{array}{l}\text { Ear shank } \\
\text { internode }\end{array}$ & Tassel \\
\hline$\overline{S C 124}$ & 14 & $14(22)^{\star * \star}$ & $14(22)$ & $14(22)$ & $86(68)$ & $18(25)$ & $13(21.1)$ & $4(11.5)$ \\
\hline SC155 & 54 & $54(47.3)$ & $54(47.3)$ & $50(45)$ & $46(42.7)$ & $33(35.1)$ & $23(28.7)$ & $18(25.1)$ \\
\hline
\end{tabular}

LSD (0.05) for symptomatic infection; plant parts $=8.1$, for hybrids $=6.6$ and for interaction $=$ 11.6. LSD (0.05) for asymptomatic infection; plant parts $=8.5$, for hybrids $=7.0$ and for interaction $=12.6$. LSD assayed from transformed data to arcsine.

* Recovery \% represents the number of plants with symptoms of late wilt disease exhibited C. maydis on PDYA divided by the total grown plants then multiply by 100.

** Recovery \% represents the number of plants exhibited $C$. maydis on PDYA from the healthy appearing plants multiply by 100 . $^{\star \star \star}$ transformed data.

\section{Anatomical study:}

The anatomy of stained, transverse sections of maize stalk fits the previous description by Esau (1965) (Fig.4). Fungal hyphae were not visible in any of the two non infected maize hybrids, SC124 and SC155, (control plants). In both sections of the tolerant hybrid, SC124, and the susceptible ones, SC155, vessel elements of plants with symptomatic infection were occluded by the agent. However, the susceptible hybrid was more occluded than the resistant ones (Fig.4-1\&2).Whereas, sections of the two hybrids with asymptomatic infection showed slight hyphal growth into vessel elements (Fig.4-3\&4). 
El-Naggar, A. A. A.

Fig. 3: Mean of vascular bundles number / $0.49 \mathrm{~mm}^{2}$ of area of maize stalk section (A), metaxylum and protoxylum cells number and diameter (B\&C) and (D\&E) respectively and maximum \& minimum of scleronchyma cell layers number (F\&G) in maize hybrids SC124 and SC155, with symptomatic and asymptomatic infection by $C$. maydis compared with their healthy plants. indicates a significant differences between measured anatomical parameters in the two hybrids. 


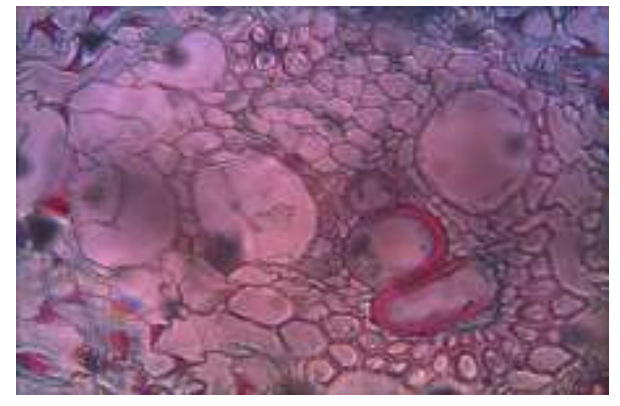

Fig. 4: Portions of a transverse sections of maize stalk of; 1 , tolerant maize hybrid, SC124 with symptomatic infection by $C$. maydis showing vessel elements, one of which is semi occluded and others contain a few mycelium (X40). 2, susceptible maize hybrid, SC155 with symptomatic infection showing collapsed cortex, and vessel elements one of which is occluded and others contain mycelium (X40 with slight zoom). $3 \& 4$, tolerant and susceptible maize hybrids, SC124 and SC155 with asymptomatic infection showing vessel elements contain a slight mycelium (X40). 5\&6, tolerarot and susceptible maize hybrids, SC124 and SC155 with no infection showing vessel elements free from the agent. Cortex (C), mycelium (M), metaxylem (MX), protoxylem (PX) and scleronchyma cell layer (SCL). 
The susceptible hybrid, SC155, showed more significant differences in number of their vascular bundles $/ 0.49 \mathrm{~mm}^{2}$ than that of the tolerant ones, SC124, under symptomatic and asymptomatic infection by $C$. maydis (Fig.3A). At the same time there were no differences between the two hybrids with non infected plants. However, the number of metaxylum and protoxylum cells of sections of the two hybrids were not varied significantly with symptomatic, asymptomatic infection and noninfected plants (Fig.3B\&C). With respect to metaxylum and protoxylum cells diameter (Fig. 3D\&E), only with non-infected plants (control) protoxylum cell diameter of SC155 had more diameters (32.8um) than SC124 (26um). Finally, the tolerant hybrid SC124 had more significant variation in their maximum scleronchyma cells layer (5.7, 5.6 and 5.6 / vascular bundle) than the susceptible ones (4, 4 and 4 / vascular bundle) with plants of symptomatic, asymptomatic and no infection respectively (Fig. 3F\&G).

\section{DISCUSSION}

Late wilt is one of the most persistent and destructive diseases of maize in Egypt. The higher recovery percentage of $C$. maydis from symptomatic and asymptomatic maize plants in the above ground parts reveled that the agent not only had the ability to invade both the most tolerant and susceptible maize plants but also takes away from above ground internode to ear shank internode and tassel internode. Our finding is some consistent with the observation of Sabet et al. (1966) they reported that C. maydis was observed close to the nodes up to the fourteenth one and also present in the cob stalk of naturally and artificially infected plants with symptoms of late wilt disease. At the same time, this result is in contrast to earlier work in which $C$. maydis attacks only the susceptible hybrids (EL-Fangary, 1970). C. maydis has been documented by El-Naggar and Sabry (2011) as a pathogen causing asymptomatic infection of maize plants and the plants depend on the tolerance as a tool of defense against the agent.

Anatomical study revealed that the number of vascular bundles / 0.49 $\mathrm{mm}^{2}$ of area in section of susceptible maize hybrid SC155 more significant in plants with symptomatic and asymptomatic infection than non infected ones. This may be due to the shrinking occurred during development of $C$. maydis symptoms which resulted in collection of vascular bundles near to each other in plants with symptoms. Our results also are inconsistent with results of Abd El-Rahim et al. (1998) who found that infection by $C$. maydis resulted in a reduction of the number of vascular bundles in the cross section of maize internode.

Our anatomical study revealed that scleronchyma cell layers number serve as a specific structural factor in tolerant hybrid which may be play a role in decreasing infection or delaying symptoms development caused by the agent in symptomatic and asymptomatic infection respectively. This results agree with those of Saeed et al. (1990) who concluded that vascular bundles of maize roots of resistant inbred lines to late wilt disease had higher contents of sclerenchyma cells than those of susceptible lines. 
Because of, the presence of $C$. maydis inside maize kernels was demonstrated in earlier work (Michail et al., 1999 and Samra et al., 1966), its wide spread in tested plant parts under study and cob (unpublished data) of symptomatic and seemingly healthy plants (plants with asymptomatic infection) of most tested hybrids, as well as fungal colonized in vascular bundles as obtained in our study, so the agent causes systemic infection.

Our findings and those reported by other workers showed that the disease cycle of this agent could be divided into the following stages; first, the agent grows superficially on maize roots, producing hyphae with short, brown, thick-walled, and swollen cells. It progresses inter- and intra-cellularly reaching to the root endodermis and the xylem after15 and 21days after sowing respectively. After the agent penetrates the xylem, it grows slowly at first but after 5 weeks grows faster upward (El-Fangary, 1970 \& Mansour, 1969). After 90 days of sowing the agent reaches to ear shank, cob and tassel (our findings). After the causal agent penetrates the cob through the ear branch, extends through the funiculus to the kernels (Michail et. al., 1999). Emerge plants from colonized kernels is infected (Samra et al., 1966). Also the agent returned again from debris of infected plants to the soil and the cycle returned at the following season.

Finally maize plants with asymptomatic infection by $C$. maydis create a dilemma for evaluating materials and seed production even though symptomatic plants are avoided. So we need an effective method(s) for fungal elimination from maize kernels.

\section{REFERENCES}

Abd El-Ghani, H. S. 1987. Studies on stalk rot disease of corn in Egypt. Ph.D. Thesis, Fac. of Agric. Ain Shams Univ. 289 pp.

Abd El-Rahim M. F., Fahmy, G. M., and Fahmy, Z. M. 1998. Alterations in transpiration and stem vascular tissues of two maize cultivars under conditions of water stress and late wilt disease. Plant path. 47: 216223.

El-Fangary, M.1970. Mechanism of resistance against the late-wilt disease in certain maize hybrids. Al-Azhar Univ. Egypt, PP.85.

El-Naggar, A.A.A., and Sabry, A. M. 2011. Asymptomatic infection of maize late wilt caused by Cephalosporium maydis. J. Plant prot. and Path., Mansoura Univ. 12: 1081-1087.

Johanson, D. A. 1940. Plant microtechnique.Mc Graw-Hill Book Co. Inc., New Yourk, 532pp.

Mansour, I. M. 1969. Studies on stalk-rots of maize in U.A.R. further investigations on the late-wilt and black-bundle disease. Ph.D Theses. Fac. of Agric., Cairo Univ., pp 190.

Michail, S. H., Abou-Elseoud, M. S., and Eldin, M. S.N. 1999. Seed health testing of corn for Cephalosporium maydis. Acta-Phytopathologica-etEntomologica-Hungarica 34:35-41.

Payak, M.M., Lal, S., Lilaramani, J., and Renfro, B. L. 1970. Cephalosporium maydis a new threat to maize in India. Ind Phytopathol 23:562-569. 
El-Naggar, A. A. A.

Pecsi, S., and Nemeth, L. 1998. Appeaance of Cephalosporium maydis Samra, sabet \& Hingorani in Hungary. Facult Landbouw en Toegepaste Biolog Wetenschappen, Unver Gent 63:873-877.

Sabet, K. A., Zaher, A. M., Samra, A. S. and Mansour, I. M. 1970. Pathogenic behaviour of Cephalosporium maydis and C. acromonium. Ann. Appl. Biol. 66:257-263.

Sabet, K. A., Samra, A. S. and Mansour, I. M. 1966. Late-Wilt disease of maize and a study of the causal organism In: Investigations on stalk-rot disease of maize in U.A.R. (Egypt). Ministry of Agriculture Editing, Puplication and Bibliography control, 8-45.

Saeed, F.A., Abou-Elseoud, M.S. and Darwish, Azziza, K. 1990. Anatomical structure of corn roots in relation to their resistance to late wilt disease. Assiut J. of Agric. Scie.21, 5: 179-191.

Sass, J. E. 1958. Botanical microtechnique.3nd edition, The lowa State College press, Ames, lowa, $228 \mathrm{pp}$.

Saleh, A. A., Zeller, K. A., Ismael, A. S. M., Fahmy, Z. M., El-Assiuty, E.M., and Leslie, J. F. 2003. Amplified Fragment length polymorphism (AFLP) diversity in Cephalosporium maydis from Egypt. Phytopathology 93:853-859.

Samra, A. S., Sabet, K. A., and Hingorani, M. K. 1962. A new wilt disease of maize in Egypt. Plant Dis Reptr 46: 481-483.

Samra, A. S., Sabet, K. A., and Hingorani, M. K. 1963. Late wilt disease of maize caused by Cephalosporium maydis. Phytopathology 53:402-406.

Samra, A. S., Sabet, K. A., and Abd El-Rahim, M. F. 1966. Seed transmission of stalk-rot fungi and effect of seed treatment. In: Investigations on stalk-rot disease of maize in U.A.R. (Egypt). Ministry of Agriculture Editing, Puplication and Bibliography control, 94-116. 


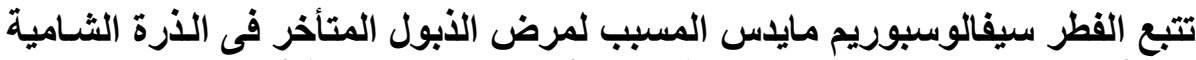

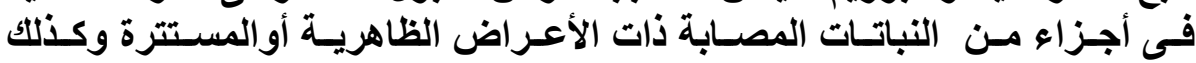

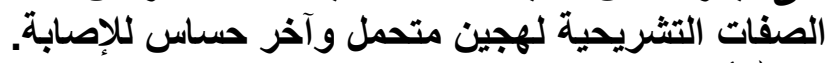

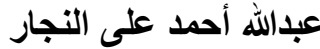
قسم بحوث امر اضل الذرة الثـامية والمحاصيل السكرية ـ معهل بحوث أمراض النباتاتـ مركز البحوث الزراعية ـ الجيزة ـ مصر الفرية

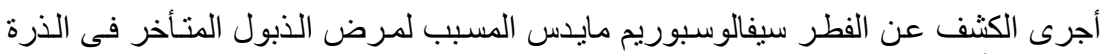

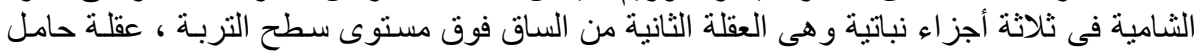

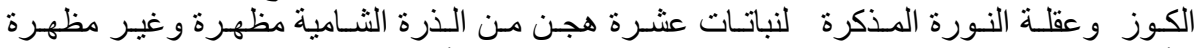

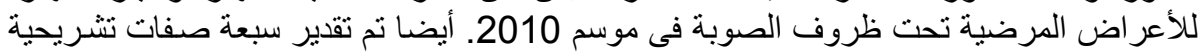

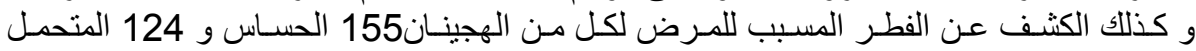

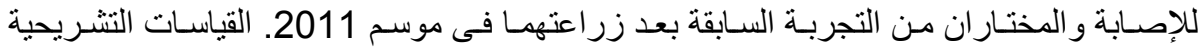

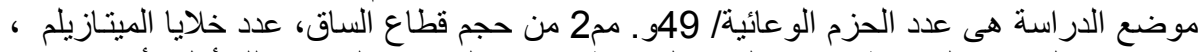

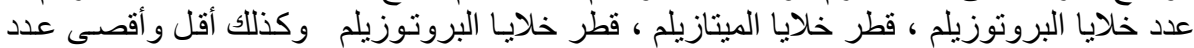

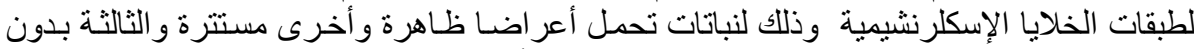

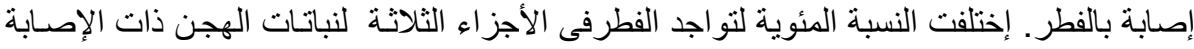

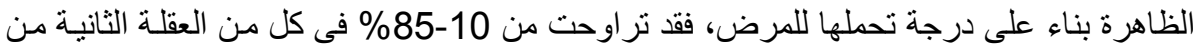

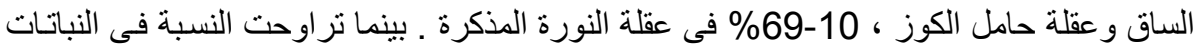

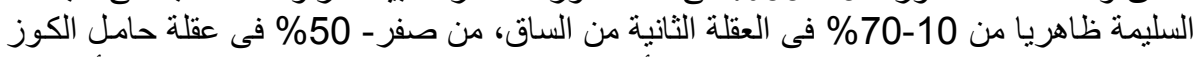

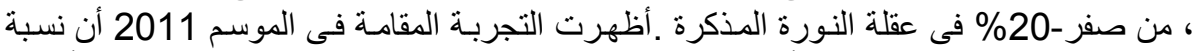

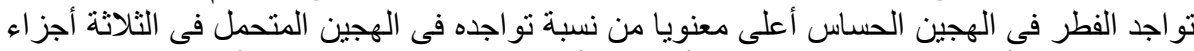

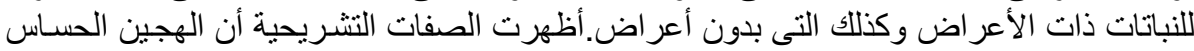

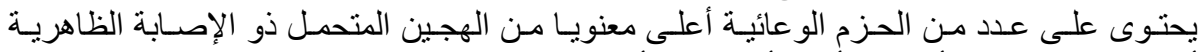

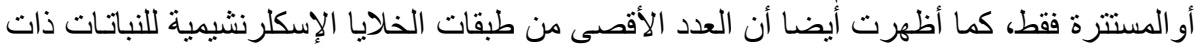

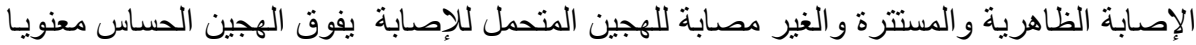

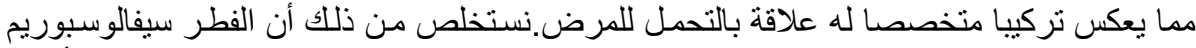

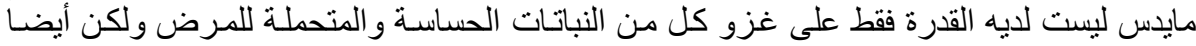

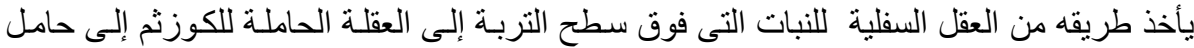
السنبلة وربما يصل إلى الحبوب عبر فولحة الكوز مكملا دورة حياته.

كلية الزراعة - جامعة المنصورة مركز البحوث الزراعية

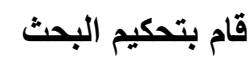

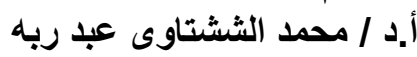

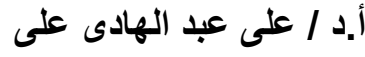

